\title{
Lost productive life years caused by chronic conditions in Australians aged 45-64 years, 2010-2030
}

Deborah J Schofield PhD, BSpPath, GradDipComp

Rupendra N Shrestha $\mathrm{PhD}, \mathrm{MSc}, \mathrm{BSc}$

Michelle Cunich

$\mathrm{PhD}, \mathrm{MEc}, \mathrm{BEC}$

Robert Tanton PhD

Simon Kelly PhD, MS, BAppSc

Megan E Passey PhD, BMed(Hons), MPH

Lennert J Veerman $\mathrm{PhD}, \mathrm{MPH}, \mathrm{MD}$

1 NHMRC Clinical Trials Centre, University of Sydney, Sydney, NSW

2 National Centre for Social and Economic Modelling

University of Canberra Canberra, ACT

3 University Centre for Rural Health, University of Sydney, Lismore, NSW.

4 University of Queensland Brisbane, QLD.

michelle.cunich@ sydney.edu.au

doi: 10.5694/mja15.00132
G lobally, there has been a substantial increase in the number of years lived with disability (YLDs) over the past 20 years. The YLDs for 1160 sequelae of 289 diseases and injuries were estimated as part of the 2010 Global Burden of Disease study: global YLDs from all causes had increased from 583 million in 1990 to 777 million in $2010 .{ }^{1}$ The main contributors to YLDs were mental and behavioural disorders, musculoskeletal disorders, and diabetes or endocrine diseases. While the Global Burden of Disease study measured YLDs at particular time points, governments have become increasingly concerned by lost productive life years (PLYs) caused by chronic disease at particular time points. We define PLYs as the loss of productivity that results from individuals not being able to participate in the labour force because of their chronic conditions. Few studies have undertaken a thorough assessment of the impact of chronic disease on labour productivity, and most have focused only on the burden of single diseases. Recent studies have shown that chronic disease can negatively affect the labour market and related outcomes, such as reduced income, greater welfare dependency and earlier retirement. ${ }^{2}$

The significant costs of premature retirement caused by chronic disease have been highlighted for most Organisation for Economic Cooperation and Development (OECD) countries. ${ }^{3}$ Premature retirement has attracted considerable attention in Australia, where unemployment is low $(5.8 \%$ in June 2014$)$ compared with other OECD countries ${ }^{4}$ and there are substantial labour shortages in a number of industries. The Australian Treasury maintains that Australia's financial position can only be improved by increasing productivity, population growth and labour force participation. ${ }^{5}$ Having a large

\section{Abstract}

Objectives: To estimate (1) productive life years (PLYs) lost because of chronic conditions in Australians aged 45-64 years from 2010 to 2030, and (2) the impact of this loss on gross domestic product (GDP) over the same period.

Design, setting and participants: A microsimulation model, Health\&WealthMOD2030, was used to project lost PLYs caused by chronic conditions from 2010 to 2030 . The base population consisted of respondents aged 45-64 years to the Australian Bureau of Statistics Survey of Disability, Ageing and Carers 2003 and 2009. The national impact of lost PLYs was assessed with Treasury's GDP equation.

Main outcome measures: Lost PLYs due to chronic disease at 2010, 2015, 2020, 2025 and 2030 (ie, whole life years lost because of chronic disease); the national impact of lost PLYs at the same time points (GDP loss caused by PLYs); the effects of population growth, labour force trends and chronic disease trends on lost PLYs and GDP at each time point.

Results: Using Health\&WealthMOD2030, we estimated a loss of 347000 PLYs in 2010; this was projected to increase to 459000 in 2030 (32.28\% increase over 20 years). The leading chronic conditions associated with premature exits from the labour force were back problems, arthritis and mental and behavioural problems. The percentage increase in the number of PLYs lost by those aged 45-64 years was greater than that of population growth for this age group (32.28\% $\vee 27.80 \%)$. The strongest driver of the increase in lost PLYs was population growth (accounting for $89.18 \%$ of the increase), followed by chronic condition trends ( $8.28 \%$ ).

Conclusion: Our study estimates an increase of 112000 lost PLYs caused by chronic illness in older workers in Australia between 2010 and 2030, with the most rapid growth projected to occur in men aged 55-59 years and in women aged 60-64 years. The national impact of this lost labour force participation on GDP was estimated to be $\$ 37.79$ billion in 2010 , increasing to $\$ 63.73$ billion in 2030 .

number of people excluded from the labour force by ill health is likely to constrain economic growth.

The impacts of an ageing population and labour shortages on a country's fiscal position have featured heavily in recent reports by supranational organisations, such as the OECD and the World Health Organization, ${ }^{3,6}$ and national governments, including the Australian Government. ${ }^{5}$ A range of policies have been adopted by the six OECD countries participating in the Workforce Aging in the New Economy (WANE) project (including Australia) to encourage the labour force participation of older workers, ${ }^{7}$ including abolishing mandatory retirement; changes to national pension and welfare systems, and disability and employment insurance; active labour-market policies; and promoting phased or gradual retirements.

If chronic conditions are one of the main barriers to labour force participation, financial incentives alone may not be sufficient to maximise the contribution of older workers. Studies from the United States and Canada have shown that employment rates among older persons with musculoskeletal conditions, ${ }^{8}$ mental illness ${ }^{9}$ and other chronic conditions are lower than those among older people without these conditions. ${ }^{10}$ Similar studies from Australia and New Zealand have found that back pain, ${ }^{11}$ arthritis, ${ }^{12}$ mental illness, ${ }^{13}$ type 2 diabetes $^{14}$ and cardiovascular 
disease ${ }^{15}$ are linked with lower labour force participation. With an ageing population, there is a risk that chronic conditions will further limit labour force capacity.

The aims of this study were to estimate (1) the PLYs lost to chronic conditions in Australians aged 45-64 years for each 5-year period from 2010 to 2030; and (2) the impact of these lost PLYs in terms of lost gross domestic product (GDP). The effects of population ageing, population growth, labour force trends and chronic disease trends are also captured in these estimates.

\section{Methods}

\section{Data}

We analysed output data from a microsimulation model called Health\&WealthMOD2030, ${ }^{16}$ which is Australia's first microsimulation model of the impact on long-term productivity over a 20-year period (2010-2030) of chronic disease and disability in the population aged 45-64 years.

The base population consists of unit record data from the cross-sectional Australian Bureau of Statistics (ABS) Surveys of Disability, Ageing and Carers (SDAC) 2003 and 2009.17,18 The records of persons aged 45-64 years and members of their family income unit were extracted. The records include data on demographic variables (age, sex, family type); socioeconomic variables (education, welfare payments); labour force variables (labour force participation, retirement); and health variables (chronic conditions, type and extent of disability).

The Australian Population and Policy Simulation Model (APPSIM) ${ }^{19}$ was used to age the SDAC data to represent the expected population in 2030. APPSIM is a dynamic population microsimulation model developed by the National Centre for Social and Economic Modelling (NATSEM) at the University of Canberra in collaboration with 12 Australian Government departments. APPSIM is based on a $1 \%$ sample from the 2001 ABS Census of
Housing and Population (the ABS Household Sample File Australia 2001). ${ }^{19}$ It simulates all major lifetime events experienced by Australians on the basis of the probability of their occurring to people in Australia. Simulated snapshots of the Australian population from 2010 to 2030 generated by APPSIM were used in this study.

To account for epidemiological trends in chronic conditions, we applied the same trends in incidence that were used in the 2003 Australian Burden of Disease and Injury Study, ${ }^{16,20}$ which projected trends for the period 2003-2023, after which it was assumed that time rates would stabilise. We calculated proportional changes in the prevalence of chronic conditions and applied these to the corresponding diseases in the SDAC data, aggregated into the following categories: stroke, cancer (almost stable in men and women), ischaemic heart disease (decreasing rate in men and women), type 2 diabetes (increasing rate in men and women) and chronic obstructive pulmonary disease (stable in men; increasing rate in women). In the absence of data about trends, the rates for all other conditions were assumed to remain stable. Based on proportional changes, the prevalence of chronic conditions in Australians aged 45-64 years was projected for 2010 and 2030 by 5 -year age groups and sex.

To account for population growth and trends in labour force participation in our PLY projections, we used 2013-2014 population and labour force projections provided by the Australian Treasury. We extracted population projections and projected full-time and part-time employment rates to 2030 for Australians aged 45-64 years by 5-year age groups and sex. ${ }^{16}$

The SDAC 2003 and 2009 data were separately reweighted to match the 2010 Australian population according to the ABS GREGWT reweighting algorithm, ${ }^{16}$ which takes into account key demographic and other changes in the population between 2003 and 2009. After reweighting, the datasets were combined and the weights halved so that the total weighted population in this new dataset matched the 2010 Australian population. A diagram of how the tools and datasets (both the source data and the datasets assembled thereafter) were used in this study is included in Appendix 1.

Our use of ABS SDAC 2003 and 2009 data was approved by the ABS Microdata Review Panel.

\section{Labour force participation and chronic conditions}

In the SDAC 2003 and 2009 surveys, respondents were asked to nominate their current labour force status, with the following options:

- Employed working full-time;

- Employed working part-time;

- Unemployed looking for full-time work;

- Unemployed looking for part-time work;

- Not in the labour force; and

- Not applicable.

For those who were not in the labour force, the main reason for not looking for work was also sought; in particular, respondents were asked whether they were out of the labour force because of their "own ill health or disability". Respondents were also asked whether they had a long-term condition and, if so, to nominate the type of condition they had from a list of 80 conditions and injuries. Those identified as being out of the labour force due to ill health or disability were classified in this study as having lost PLYs because of a chronic condition. ${ }^{17,18}$

\section{Statistical analysis}

Outputs from Health\&WealthMOD2030 were used to generate descriptive statistics of the relationship between chronic disease, PLYs lost and labour force participation of older workers in 2010, 2015, 2020, 2025 and 2030, by age group and sex.

We analysed the expected growth in the number of people aged 45-64 years who would lose PLYs (and the growth in the number of persons employed with and without chronic disease) at each of the five time 
points. Projected changes were driven by population growth, population ageing, chronic condition trends and labour force trends (by age group and sex). The contributions of each driver to the number of workers aged 45-64 years in each of the labour force groups to 2030 were disaggregated. All analyses were conducted in SAS V9.3 (SAS Institute).

\section{GDP equation}

The impact of PLYs lost to chronic disease in the 45-64-year-old age group on national GDP was calculated using the GDP formula of the Australian Treasury:

$$
\begin{aligned}
\mathrm{GDP}= & (\mathrm{GDP} / \mathrm{H}) \times(\mathrm{H} / \mathrm{EMP}) \times(\mathrm{EMP} / \mathrm{LF}) \\
& \times(\mathrm{LF} / \text { Pop } 15+) \times \text { Pop } 15+
\end{aligned}
$$

where $\mathrm{H}$ is the total number of hours worked, EMP is the total number of persons employed, LF is the size of the labour force, and Pop15+ is the population aged 15 years or more. ${ }^{21}$

\section{Results}

Of the 25104 people aged 45-64 years surveyed in the combined SDACs 2003 and 2009, 1410 (5.62\%) were out of the labour force because of a chronic condition, 12682 $(50.51 \%)$ were employed full-time, $5185(20.65 \%)$ were employed part- time, and 5827 (23.21\%) were unemployed or not in the labour force in 2010 for reasons other than ill health. After weighting, these data corresponded to 347000 PLYs lost because individuals had withdrawn from the labour force due to ill health, 3025000 individuals employed fulltime, 1122000 employed part-time and 1086000 unemployed or not in the labour force for reasons other than ill health (total population, 5580000 people). The projected number of PLYs for 2030 was 459000 in a population of 7130000 , an increase of $32.28 \%$. In terms of persons in the labour force, it is projected that 3979000 individuals will be employed full-time, 1576000 part-time and 1116000 will be unemployed or not in the labour force for reasons other than ill health (Box 1). Growth in the number of people employed full- or part-time with a chronic condition (35.12\% and $42.99 \%$, respectively) was greater than growth in the number of people employed full- or part-time without a chronic condition $(28.31 \%$ and $37.33 \%$, respectively)

Box 2 shows the number of PLYs lost in those aged 45-64 years in 2010 and 2030, according to the main chronic condition. Back problems were the major contributors to PLYs lost at each time point $(23.27 \%$ of PLYs lost to chronic conditions in 2010, $21.37 \%$ in 2030). Other important contributors were arthritis (13.26\% in $2010,13.31 \%$ in 2030), mental and behavioural disorders (other than depression; $9.58 \%$ in $2010,9.49 \%$ in $2030)$ and depression (7.06\% in 2010, $6.33 \%$ in 2030). There was little change over time in the relative proportions of people out of the labour force with each condition.

Box 3 shows the contributions of population growth, ageing, chronic disease trends and labour force trends to the increase in PLYs lost and labour force participation (with and without chronic illness) from 2010 to 2030. Of the projected $32.28 \%$ increase in PLYs lost to ill health between 2010 and $2030,89.18 \%$ is due to population growth (including 3.97\% attributable to ageing) and $8.28 \%$ to chronic disease trends. Population growth is the largest driver of fulltime employment, whereas labour force trends are the largest driver of part-time employment.

The contribution of population growth, chronic condition trends and labour force trends to the estimated increase in PLYs lost for those aged 45-64 years (and the different labour force groups) from 2010 to 2030 (by age group and sex) are shown in Appendix 2. The largest projected increase in PLYs lost due to chronic conditions is for men aged 55-59 years $(38.39 \%)$ and women aged 60-64 years $(38.90 \%)$. There is also

\begin{tabular}{|c|c|c|c|c|c|c|c|}
\hline \multirow[b]{2}{*}{ Labour force status } & \multirow{2}{*}{$\begin{array}{c}\text { Survey } \\
\text { records (\%) }\end{array}$} & \multicolumn{5}{|c|}{ Weighted population (\%) } & \multirow{2}{*}{$\begin{array}{c}\text { Growth, } \\
2010-2030\end{array}$} \\
\hline & & 2010 & 2015 & 2020 & 2025 & 2030 & \\
\hline $\begin{array}{l}\text { Employed full-time with a } \\
\text { chronic condition }\end{array}$ & $\begin{array}{c}6076 \\
(24.20 \%)\end{array}$ & $\begin{array}{l}1452000 \\
(26.03 \%)\end{array}$ & $\begin{array}{l}1565000 \\
(22.92 \%)\end{array}$ & $\begin{array}{l}1722000 \\
(27.02 \%)\end{array}$ & $\begin{array}{c}1830000 \\
(27.41 \%)\end{array}$ & $\begin{array}{l}1962000 \\
(27.52 \%)\end{array}$ & $35.12 \%$ \\
\hline $\begin{array}{l}\text { Employed full-time without } \\
\text { a chronic condition }\end{array}$ & $\begin{array}{c}6606 \\
(26.31 \%)\end{array}$ & $\begin{array}{l}1572000 \\
(28.18 \%)\end{array}$ & $\begin{array}{c}1653000 \\
(24.21 \%)\end{array}$ & $\begin{array}{l}1786000 \\
(28.02 \%)\end{array}$ & $\begin{array}{c}1864000 \\
(27.92 \%)\end{array}$ & $\begin{array}{l}2017000 \\
(28.29 \%)\end{array}$ & $28.31 \%$ \\
\hline $\begin{array}{l}\text { Employed part-time with a } \\
\text { chronic condition }\end{array}$ & $\begin{array}{c}2812 \\
(11.20 \%)\end{array}$ & $\begin{array}{l}621000 \\
(11.13 \%)\end{array}$ & $\begin{array}{c}1565000 \\
(22.92 \%)\end{array}$ & $\begin{array}{l}769000 \\
(12.06 \%)\end{array}$ & $\begin{array}{l}825000 \\
(12.36 \%)\end{array}$ & $\begin{array}{l}888000 \\
(12.45 \%)\end{array}$ & $42.99 \%$ \\
\hline $\begin{array}{l}\text { Employed part-time without } \\
\text { a chronic condition }\end{array}$ & $\begin{array}{c}2373 \\
(9.45 \%)\end{array}$ & $\begin{array}{l}501000 \\
(8.98 \%)\end{array}$ & $\begin{array}{l}536000 \\
(7.85 \%)\end{array}$ & $\begin{array}{l}594000 \\
(9.32 \%)\end{array}$ & $\begin{array}{l}632000 \\
(9.47 \%)\end{array}$ & $\begin{array}{l}688000 \\
(9.65 \%)\end{array}$ & $37.33 \%$ \\
\hline $\begin{array}{l}\text { Unemployed or not in the labour } \\
\text { force for reasons other than } \\
\text { ill health }\end{array}$ & $\begin{array}{c}5827 \\
(23.21 \%)\end{array}$ & $\begin{array}{c}1086000 \\
(19.47 \%)\end{array}$ & $\begin{array}{l}1129000 \\
(16.53 \%)\end{array}$ & $\begin{array}{l}1090000 \\
(17.10 \%)\end{array}$ & $\begin{array}{c}1092000 \\
(16.35 \%)\end{array}$ & $\begin{array}{l}1116000 \\
(15.65 \%)\end{array}$ & $2.76 \%$ \\
\hline $\begin{array}{l}\text { Productive life years lost due } \\
\text { to chronic conditions in each year }\end{array}$ & $\begin{array}{c}1410 \\
(5.62 \%)\end{array}$ & $\begin{array}{l}347000 \\
(6.22 \%)\end{array}$ & $\begin{array}{l}380000 \\
(5.57 \%)\end{array}$ & $\begin{array}{l}413000 \\
(6.48 \%)\end{array}$ & $\begin{array}{l}434000 \\
(6.50 \%)\end{array}$ & $\begin{array}{l}459000 \\
(6.44 \%)\end{array}$ & $32.28 \%$ \\
\hline Total population & 25104 & 5580000 & 5945000 & 6374000 & 6677000 & 7130000 & $27.80 \%$ \\
\hline
\end{tabular}

1 Labour force status of Australians aged 45-64 years, projected to 2030 
2 Main chronic conditions of people aged 45-64 years not in the labour force due to ill health in 2010 and 2030

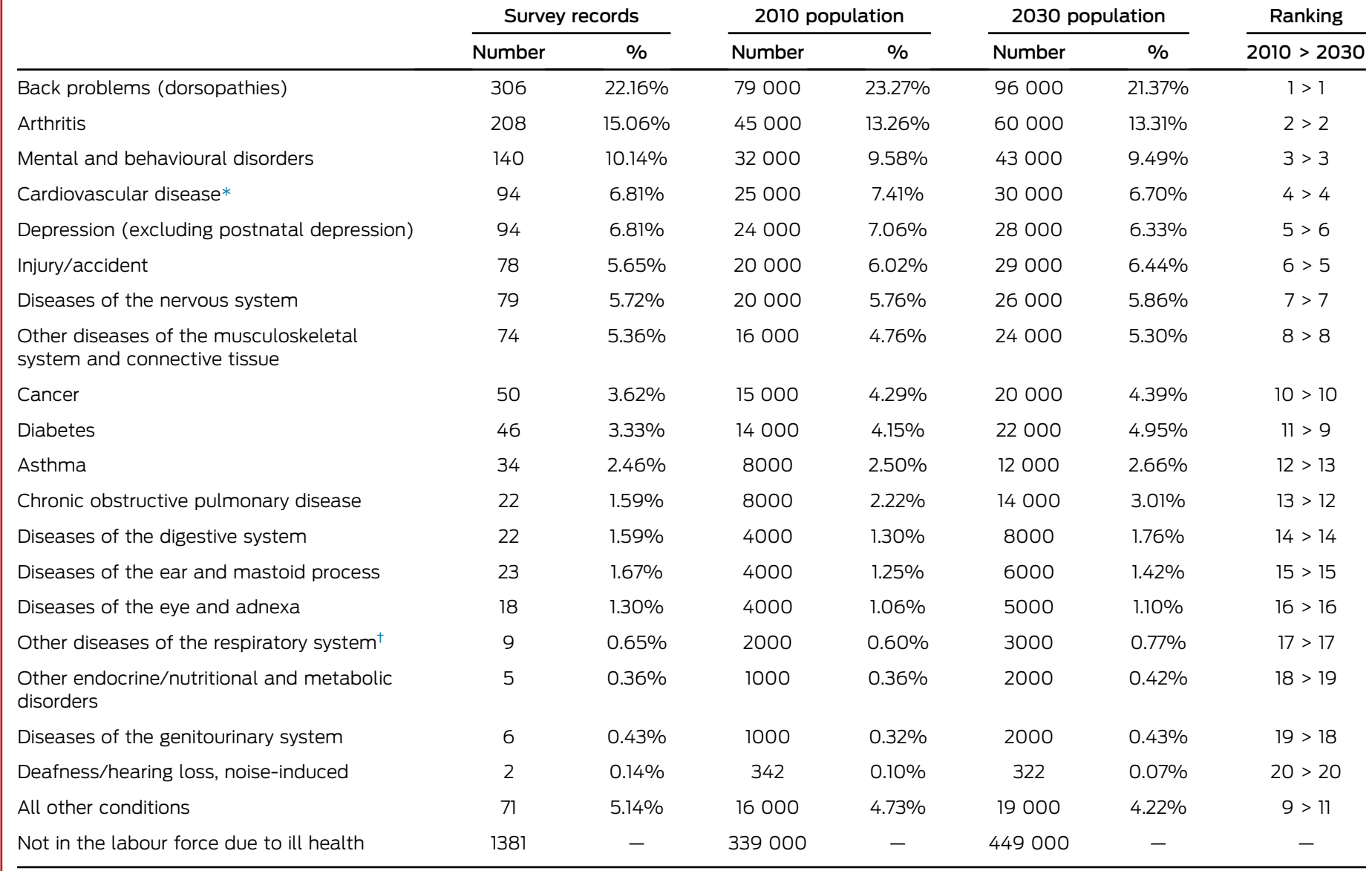

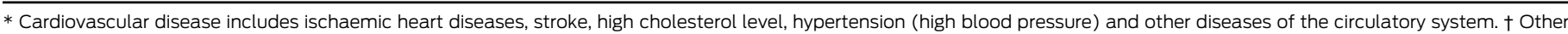
diseases of the respiratory system include bronchitis/bronchiolitis, respiratory allergies (excluding allergic asthma) and emphysema.

considerable projected growth in employment linked with Treasury's projections of rising demand for labour and labour force participation trends. ${ }^{16}$ For men employed full-time, the largest increase in employment is projected to occur among those aged 60-64 years $(37.51 \%)$; the largest increase for women is projected to occur among those aged $55-59$ years $(63.43 \%)$, almost twice the increase for older men.

Population growth makes the largest contribution to growth in both PLYs lost and in the labour force between 2010 and 2030. The contribution of disease trends to PLYs lost, after removing population and labour force trends, was largest for men out of the labour force because of ill health and who were aged 50-54 years
$(10.23 \%)$ or $55-59$ years $(9.62 \%)$. For women, the contribution of disease trends was greatest in those aged 60-64 years who were not in the labour force because of a chronic condition $(13.04 \%)$. The positive contribution of labour trends to growth in full-time employment was larger in every age group for women than for men, reflecting changes in female labour force participation and education. ${ }^{5}$ For part-time employment, large reductions were projected for men aged 45-49 and 50-54 years ( $26.69 \%$ and $9.66 \%$, respectively), and large increases for women of all ages (Appendix 2).

As a result of the 347000 PLYs lost because of a chronic condition in individuals aged 45-64 years, there was an estimated loss of GDP of $\$ 37.79$ billion in 2010. In 2030, the loss of 459000 PLYs will result in a projected GDP loss of $\$ 63.73$ billion (expressed in 2010 dollars; Box 4). These projected reductions in GDP correspond to $9.47 \%$ of GDP associated with the 45-64-year-old subpopulation in 2010 and to $10.29 \%$ in 2030 .

If the projected growth in the prevalence of chronic conditions between 2010 and 2030 was only half that assumed by our main analysis, an estimated 453000 PLYs would be lost by those aged 45-64 years because of chronic conditions in 2030, resulting in a projected loss of GDP of $\$ 62.89$ billion. However, if the projected growth is doubled, the estimated PLYs lost would be 589000 in 2030, resulting in a projected GDP loss of $\$ 81.78$ billion (expressed in 2010 dollars). 
3 Contribution of main drivers to growth in productive life years lost and labour force participation between 2010 and 2030

\begin{tabular}{|c|c|c|c|c|c|}
\hline \multirow[b]{2}{*}{ Driver } & \multicolumn{2}{|c|}{ Employed full-time } & \multicolumn{2}{|c|}{ Employed part-time } & \multirow{2}{*}{$\begin{array}{l}\text { Productive life } \\
\text { years lost due to } \\
\text { chronic conditions }\end{array}$} \\
\hline & $\begin{array}{l}\text { With a chronic } \\
\text { condition }\end{array}$ & $\begin{array}{l}\text { Without a chronic } \\
\text { condition }\end{array}$ & $\begin{array}{l}\text { With a chronic } \\
\text { condition }\end{array}$ & $\begin{array}{l}\text { Without a chronic } \\
\text { condition }\end{array}$ & \\
\hline Population growth (total) & $81.97 \%$ & $94.00 \%$ & $63.21 \%$ & $70.43 \%$ & $89.18 \%$ \\
\hline $\begin{array}{l}\text { Growth due to population ageing } \\
\text { (a component of total population growth) }\end{array}$ & $-0.92 \%$ & $-3.32 \%$ & $1.23 \%$ & $-3.32 \%$ & $3.97 \%$ \\
\hline Chronic disease trends & $1.78 \%$ & $-4.31 \%$ & $0.53 \%$ & $-2.73 \%$ & $8.28 \%$ \\
\hline Labour force trends & $10.42 \%$ & $8.39 \%$ & $26.45 \%$ & $26.78 \%$ & NA \\
\hline Interaction effects & $5.83 \%$ & $1.92 \%$ & $9.81 \%$ & $5.52 \%$ & $2.54 \%$ \\
\hline
\end{tabular}

4 Loss of GDP arising from lost productive life years caused by chronic ill health in Australians aged 45-64 years, 2010-2030 (expressed in \$, billions)

\begin{tabular}{lllll}
2010 & 2015 & 2020 & 2025 & 2030 \\
\hline 37.79 & 44.51 & 50.54 & 56.39 & 63.73 \\
\hline GDP = gross domestic product. & & & \\
\hline
\end{tabular}

\section{Discussion}

Using output from Health\&WealthMOD2030, we projected the number of PLYs lost because of chronic health conditions in Australians aged 45-64 years from 2010 to 2030. We established that there were 347000 PLYs lost due to chronic disease in those aged 45-64 years in 2010 , projected to increase to 459000 in 2030.

The PLYs lost among older workers due to chronic conditions are likely to have significant flow-on effects for individuals and governments. Our group has previously calculated the substantial impacts of ill health on all-source income, taxation and welfare payments for older workers (and government) in Australia in 2010. 2,13 We also found that ill health resulted in significantly lower incomes and lower accumulated wealth and savings for those who had retired early because of their ill health ${ }^{22}$ and a greater risk of poverty. ${ }^{23}$

Our study has a number of limitations. First, the impact of chronic disease on labour force participation is based on respondents' self-reports of their main chronic condition. Although self-reported health is considered a valid parameter, ${ }^{24}$ bias in the results cannot be excluded. Second, the SDACs 2003 and 2009 provided cross-sectional data. It is therefore possible to identify correlations but not causal relationships between parameters. It should be noted, however, the SDAC surveys included a specific category for being out of the labour force because of chronic disease ("own ill health or disability") that could only be selected by those who had first stated they were not in the labour force. We thus identified those who are not in the labour force and then the main reason for their not being in the labour force (eg, ill health).

As the population ages, it is crucial that governments continue to adopt measures that retain as many working-age individuals in the labour force as possible. The former Federal Treasurer Wayne Swan noted in his 2011-12 Budget speech that: “... our economy can't afford to waste a single pair of capable hands." ${ }^{2 b}$ Retaining older people in the workforce will enable greater economic growth and provide government revenue for spending on vital services, including health care. ${ }^{5}$

Achieving these goals requires governments to take a more holistic approach to increasing labour force participation among older workers - an approach that considers the interaction of health, illness prevention, work capacity and government priorities (such as economic growth). Directing resources towards the introduction of effective interventions to prevent and treat the chronic conditions associated with the highest rates of premature exit from the labour force by older workers (back problems, arthritis, mental and behavioural disorders) is likely to improve the work capacity of this group (or, put another way, reduce the loss of PLYs predicted by our study) and thereby Australia's future finances.

Acknowledgements: The development of the microsimulation model used in this research, Health\&WealthMOD2030, is funded by the Australian Research Council (under grant LP100100158); Pfizer Australia is a partner to the grant. Megan Passey is supported by fellowships from the National Health and Medical Research Council, the Cancer Institute NSW and the Sydney Medical School Foundation.

Competing interests: We are financially independent of the funding sources, and the funding sources (including Pfizer Australia) played no part in the research design, the analysis, formulation or interpretation of the results, the decision to publish the research findings, or in any other aspect of the research process.

(c) 2015 AMPCo Pty Ltd. Produced with Elsevier B.V. All rights reserved. 
1 Vos T, Flaxman AD, Naghavi M, et al. Years lived with disability (YLDs) for 1160 sequelae of 289 diseases and injuries 1990-2010: a systematic analysis for the Global Burden of Disease Study 2010. Lancet 2012; 380: 2163-2196.

2 Schofield DJ, Shrestha RN, Passey ME, et al. Chronic disease and labour force participation among older Australians. Med J Aust 2008; 189: 447-450. https://www.mja.com.au/journal/2 008/189/8/chronic-disease-andlabour-force-participation-amongolder-australians

3 Organisation for Economic Cooperation and Development. Sickness, disability and work: breaking the barriers. Paris: OECD Publishing, 2010. http://ec.europa.eu/health/mental_ health/eu_compass/reports_studies/ disability_synthesis_2010_en.pdf (accessed Jul 2015).

4 Australian Bureau of Statistics. Labour force, Australia, June 2014. Canberra: ABS, 2014. (ABS Cat. No. 6202.0.) http://www.ausstats.abs.gov.au/ ausstats/meisubs.nsf/0/4766D879F8 9E6574CA257D100013F55B/\$File/62 020_jun\%202014.pdf (accessed Jul 2015).

5 Swan A, The Treasury. Australia to 2050: future challenges. Canberra: Commonwealth of Australia, 2010. http://archive.treasury.gov.au/igr/igr201 0/report/pdf/IGR_2010.pdf (accessed Jul 2015).

6 World Health Organization. Facing the facts: the impact of chronic disease in high income countries. Geneva: World Health Organization, 2005. http:// www.who.int/chp/chronic_disease_ report/media/info_sheet_hi_income.pdf (accessed Jul 2015).

7 Cooke M. Policy changes and the labour force participation of older workers: evidence from six countries. Can J Aging 2006; 25: 387-400.

8 Yelin EH, Trupin LS, Sebesta DS. Transitions in employment, morbidity, and disability among persons ages 51-61 with musculoskeletal and nonmusculoskeletal conditions in the US, 1992-1994. Arthritis Rheum 1999; 42: 769-779.
9 Begley CE, Annegers JF, Swann AC, et al. The lifetime cost of bipolar disorder in the US: an estimate for new cases in 1998. Pharmacoeconomics 2001; 19: 483-495.

10 Moore R, Mao Y, Zhang J, Clarke K. Economic burden of illness in Canada, 1993. Ottawa: Canadian Public Health Association, 1997. http://publications. gc.ca/collections/collection_2013/aspcphac/H21-136-1993-eng.pdf (accessed Jul 2015).

1 Schofield DJ, Shrestha RN, Percival R, et al. The personal and national costs of early retirement because of spinal disorders: impacts on income, taxes, and government support payments. Spine J 2012; 12: 1111-1118.

12 Schofield DJ, Shrestha RN, Percival R, et al. The personal and national costs of lost labour force participation due to arthritis: an economic study. BMC Public Health 2013; 13: 1-10.

13 Schofield DJ, Shrestha RN, Percival R, et al. Quantifying the effect of early retirement on the wealth of individuals with depression or other mental illness. Br J Psychiatry 2011; 198: 123-128.

14 Schofield DJ, Cunich M, Shrestha RN, et al. The impact of diabetes on the labour force participation and income poverty of workers aged 45-64 years in Australia. PLOS One 2014; 9: e89360.

15 Schofield D, Shrestha R, Percival R, et al. The personal and national costs of CVD: impacts on income, taxes, government support payments and GDP due to lost labour force participation. Int J Cardiol 2013; 166: 68-71.

16 Schofield D, Shrestha R, Kelly S, et al. A microsimulation model of the long term economic impacts of disease on the labour force participation of Australians aged 45-64 years: what are the costs to individuals and government and the opportunities for effective interventions? Int J Microsim 2014; 7: 94-118.

17 Australian Bureau of Statistics. Information paper. Basic confidentialised unit record file: survey of disability, ageing and carers 2003 (reissue). (ABS Cat. No. Catalogue no.
4430.0.00.001.) Canberra: ABS, 2004. http://www.ausstats.abs.gov.au/ Ausstats/subscriber.nsf/0/0B656F42 F01EC683CA25704500769F3C/ \$File/4430000001_2003\%20\%28 reissue\%29.pdf (accessed Jul 2015).

18 Australian Bureau of Statistics. Disability, ageing and carers, Australia: summary of findings. 2009. Canberra: ABS, 2012. (ABS Cat. No. 4430.0.)

http://www.ausstats.abs.gov.au/ Ausstats/subscriber.nsf/0/9C2B94626 FOFAC62CA2577FA0011C431/\$File/443 00_2009.pdf (accessed Jul 2015).

19 Keegan M, Kelly S. APPSIM - Dynamic microsimulation modelling of social security and taxation. Canberra: National Centre for Social and Economic Modelling, University of Canberra, 2009. http://pandora.nla. gov.au/pan/70542/20100331-0000/ www.canberra.edu.au/No.14.pdf (accessed Jul 2015).

20 Begg SJ, Vos T, Barker B, et al. Burden of disease and injury in Australia in the new millennium: measuring health loss from diseases, injuries and risk factors. Med J Aust 2008; 188: 36-40. https:// www.mja.com.au/journal/2008/188/1/ burden-disease-and-injury-australianew-millennium-measuring-healthloss-diseases

21 Costello $P$, The Treasury. Intergenerational report 2007. Canberra: Commonwealth of Australia, 2007. http://archive.treasury.gov.au/igr/ igr2007/report/PDF/IGR_2007_final_ report.pdf (accessed Jul 2015).

22 Kelly SJ, Percival R, Schofield DJ, et al. The impact of illness on retirement finances. Econ Rec 2012; 88: 576-584.

23 Schofield DJ, Callander EJ, Shrestha RN, et al. Premature retirement due to ill health and poverty: a cross-sectional study of older workers. BMJ Open 2013; 3: e002683.

24 Wannamethee G, Shaper AG. Selfassessment of health status and mortality in middle-aged British men. Int J Epidemiol 1991; 20: 239-245.

25 Swan W. Budget speech 2011-12. Canberra: Australian Government, 2011. http://www.budget.gov.au/2011-12/ content/speech/html/speech.htm (accessed Jul 2015). 